\title{
A Cascade Disaster Caused by Geological and Coupled Hydro-Mechanical Factors-Water Inrush Mechanism from Karst Collapse Column under Confining Pressure
}

\author{
Hao Li ${ }^{1, *}$, Haibo Bai ${ }^{1, *}$ (D), Jianjun $\mathrm{Wu}^{2}$, Zhanguo Ma ${ }^{1}$, Kai Ma ${ }^{1}$, Guangming Wu ${ }^{1}$, Yabo Du ${ }^{3}$ \\ and Shixin $\mathrm{He}^{1}$ \\ 1 State Key Laboratory for Geomechanics and Deep Underground Engineering, China University of Mining \\ and Technology, Xuzhou 221116, Jiangsu, China; zgma@cumt.edu.cn (Z.M.); KKM_Ma@163.com (K.M.); \\ xiaowugm@163.com (G.W.); hs_xin@163.com (S.H.) \\ 2 Shanxi China Coal Huajin Energy Limited Liability Company, Hejin 043300, Shanxi, China; \\ jjwucumtedu@126.com \\ 3 School of Resources and Geosciences, China University of Mining and Technology, \\ Xuzhou 221116, Jiangsu, China; duyabo@cumt.cn \\ * Correspondence: hlicumtedu@126.com (H.L.); hbbaicumtedu@126.com (H.B.); \\ Tel: +86-170-7250-1644 (H.L.); +86-183-6126-1323 (H.B.)
}

Received: 23 September 2017; Accepted: 17 November 2017; Published: 23 November 2017

\begin{abstract}
The water inrush from karst collapse column (KCC) is a cascading, vicious cycle disaster caused by geological and mining activities, that can cause serious casualties and property losses. The key to preventing this risk is to study the mechanism of water inrush under confining pressure. Aiming at the investigationg the characteristics of the KCC named X1 in Chensilou mine, a series of methods, including connectivity experiments, water pressure monitoring tests in two side-walls, and numerical simulations based on plastic damage-seepage (PD-S) theory have been developed. The methods are used to test the security of the 2519 mining area, the damage thickness, pore water pressure, and seepage vector in the X1. The results indicate that the $\mathrm{X} 1$ has a certain water blocking capacity. In addition, with the decrease of confining pressure and increase of shear stress, deviatoric stress could cause the increase of permeability, the reduction of strength, and the reduction of pore water pressure in KCC. Therefore the increased effective stress in the rock will force the rock to become more fractured. Conversely, the broken rock could cause the change of stress, and further initiate new plastic strains, damage and pore water pressure until a new equilibrium is reached. This cascading water inrush mechanism will contribute to the exploitation of deep coal resources in complex geological and hydrogeological conditions.
\end{abstract}

Keywords: cascade disaster; karst collapse column; coupled hydro-mechanical model; water inrush mechanism; confining pressure

\section{Introduction}

Mine water inrush and consequent secondary disasters have caused huge losses in many countries, including USA [1], Russia [2], Hungary [3], Germany [4], Australia [5] and China [6]. As a unique geological phenomenon in north China, karst collapse column (KCC), which is caused by the karst subsidence that occurs in Ordovician limestone caves, forms cone, barrel, inclined tower or irregular shapes [7], connects coal seams and aquifers (Figure 1), and may cause serious groundwater inrush disasters under the influence of the confined water pressure and the ground pressure, including axial pressure and confining pressure [8]. 


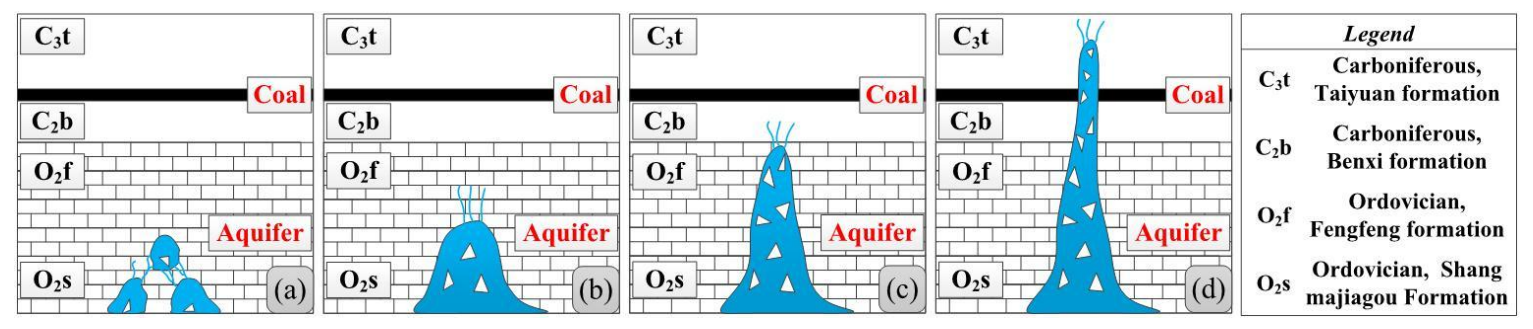

Figure 1. Formation process of KCC. (a) Connection of caves; (b) initial stage; (c) growth stage; (d) final stage.

Between the 1950s to 1990s, people mainly study the formation process, distribution law and exploration method of KCC by geological and hydrogeological theories [9-11]. In recent years, with the increase of mining depth, serious water inrush accidents from KCC have happened in many mines and attracted scholars' attention [12,13]. Different theories and methods have been used to study the water inrush mechanism of KCC. Li et al. [14] and Zhang et al. [15] assumed that the rock mass is an elastic material, and the stresses in the internal and external of KCC under the mining influence were calculated by solid mechanics theory. Yin and Zhang [16] and Ou Subei et al. [17] calculated the distribution of the stress and plastic zone of KCC under the influence of water pressure by numerical simulation method. According to the formation process of the KCC, Ma et al. [4] believed that the fluid-solid coupling theory can better reflect the geological condition of KCC, and the distribution of plastic zone and pore water pressure under the mining influence were calculated by numerical simulation. Zhang [18] simplified the floor as a clamped-clamped beam and calculated the tensile failure area of the beam under the influence of confined water pressure by material mechanics theory, the results were verified by water injection test. Zhu et al. [19] used the "strain method" to test the strain of floor rock mass during mining advance, monitoring the deformation of rock strata in different depths.

The axial stress or shear stress, deformation and range of plastic zone under the confined water pressure of Ordovician limestone are the focus of the above literature. However, they focus less on the effects of plastic strain, damage, seepage, especially the effect of confining pressure on the water inrush mechanism under complex hydrogeological conditions, including a KCC and multiple limestone aquifers in the Taiyuan formation. During the deep mining process, the variation of confining pressure could cause large plastic deformation of the KCC [20], and lead to the formation of damage zone. In this case, the pore water pressure decrease, the permeability coefficient and seepage velocity increase, and eventually, a cascade disaster is formed in the KCC.

In this paper, the 2519 mining face of Chensilou mine has been chosen as the study area, where the floor contains a KCC and three high confined aquifers, meanwhile the confining pressure is 19.3 MPa. In order to simulate the cascade effect of such complex geology and hydrogeology on the KCC, a new plastic damage-seepage coupled model that conformed to the characteristics of mechanical and hydraulics response of rock under confining pressure was established. The damage distribution and seepage vector in KCC during mining advance were obtained by programming. Instead of "strain method" and "single side-wall water injection test", a new in-situ test, that is, water pressure monitoring test in two side-walls has been developed to test the damage thickness in the KCC's side-walls where it has a high probability of water inrush. By these methods, we found that the damage thickness at the left side-wall was slightly larger than that at the right side-wall, resulting in the instantaneous seepage velocity to the maximum. But the total water inflow at the right side-wall is greater due to the reduced confining pressure. This conclusion provides a basis for coal mine safety production. 


\section{Study Area}

Compared to the late Paleozoic coalfields exploited in other parts of the world, such as the Appalachian coalfield in the United States, the Yorkshire coalfield in Great Britain, the Ruhr coalfield in Germany and the Donetz coalfield in Ukraine, there is a great risk of water inrush in the North China coalfields due to the presence of karst collapse column (KCC) or other complex geological structures [21]. Furthermore, compared to other coal mine area in North China, geological conditions in the Chensilou mine are even worse: 2519 mining face contains a KCC filled with water, the KCC directly connected three high pressure aquifer and coal seam and there is a synclinal basin in 2519 mining area. Therefore, the study of the damage and seepage law of the KCC under the mining influence can provide a reference for other KCCs in North China.

\subsection{Overview of the Chensilou Mine}

Chensilou coal mine is located northeast of Yongcheng City in Henan Province (Figure 2). In the coal seam floor, the stratigraphic succession consists of two obvious rock formations from bottom to top: Ordovician $(\mathrm{O})$, containing a thick limestone aquifer, and Carboniferous $(\mathrm{C})$, containing a coal bed, two limestone aquifers and several sandstones and mudstones. In the horizontal direction, there is a synclinal basin to the southwest of the mine.

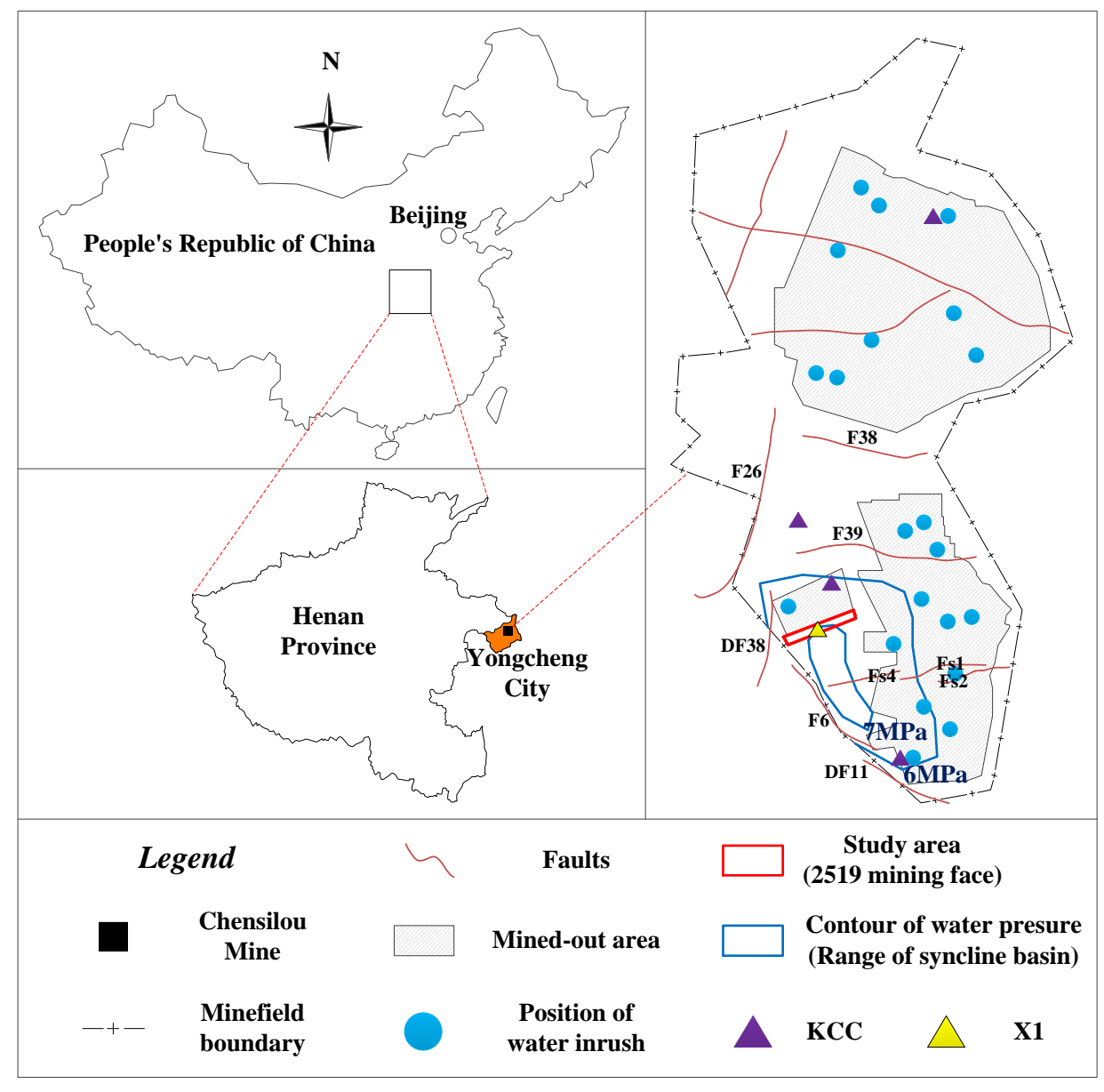

Figure 2. Location of Chensilou mine and study area.

\subsection{Engineering Situations at 2519 Mining Face}

We selected the 2519 mining face as the study area for the following three reasons: (1) as the coal in the southeastern mine has been mined, coal will now be mined in the southwest (Figure 2); 
(2) water inrush accidents have occurred more than 20 times since 1997 (Figure 2). As the mining face has advanced towards the syncline basin, geological and hydrogeological conditions have become even worse. In the east of the south part, the mining depth is $390 \mathrm{~m}$, the water pressure in the three limestone aquifers are $2.6 \mathrm{MPa}, 1.5 \mathrm{MPa}$ and $1.3 \mathrm{MPa}$ from bottom to top, the distance between the coal seam and the limestone 1 is $60 \mathrm{~m}$, and the confining pressure is $6.6 \mathrm{MPa}$. However, in the 2519 mining face, the mining depth increases to $890 \mathrm{~m}$, the water pressures in the three limestone aquifers are as high as 7.0 MPa, 3.3 MPa and 3.0 MPa from bottom to top, and the confining pressure is $28.6 \mathrm{MPa}$. The distance between the coal seam and the upper limestone aquifer is only $24 \mathrm{~m}$ (Figure 3), while the sandstone in floor is more broken due to tectonic stress in the syncline structure; (3) more serious is the fact that the 2519 mining area has a KCC named X1. According to the drilling data, the coring recovery rate (the ratio of the total length of intact rock and broken rock to drilling length) is only $52 \%, 48 \%$ and $23 \%$ in the upper, middle and lower part of X1, respectively (Figure 3). Meanwhile, the X1 connects the three limestone aquifers and coal seam, making this weak geological structure have a high risk of water inrush.

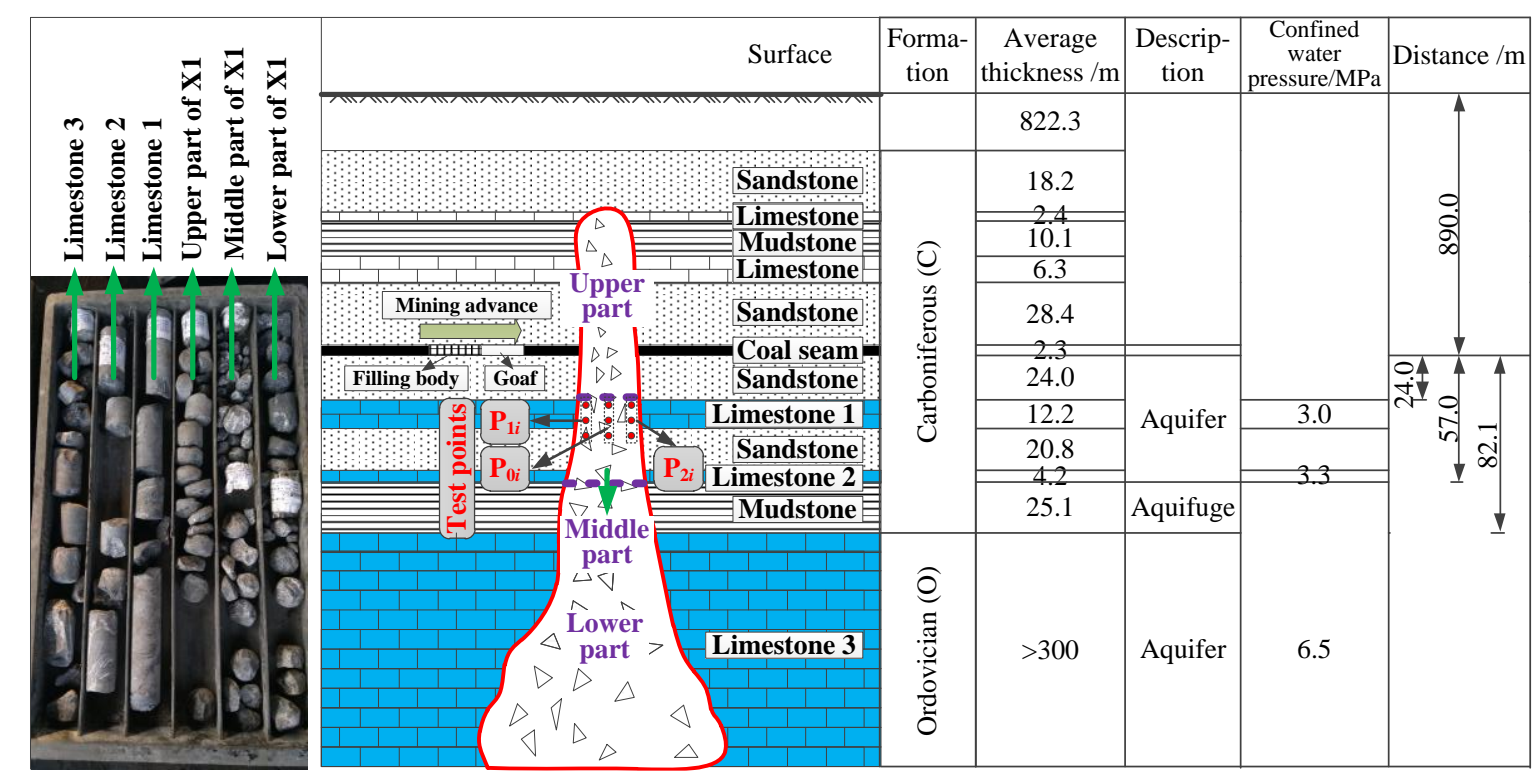

Figure 3. The profile and core of $\mathrm{X} 1$, and stratigraphic characteristics of surrounding rock.

\section{In-Situ Test}

Rock damage caused by mining activities will cause a significant change in the permeability of KCC. Thus the main purpose of in-situ test is to test the damage characteristics of KCC under the mining influence. According to the geological and hydrogeological conditions of the 2519 mining face as described in Section 2.2, it might be dangerous to directly test the damage thickness of X1 during mining advance. Therefore, a connectivity experiment was carried out firstly to test the initial permeability of the KCC.

\subsection{Connectivity Experiment}

The principle and the process of the connectivity test is a follows: three boreholes (i.e., $\mathrm{P}_{01}, \mathrm{P}_{02}$ and $\mathrm{P}_{03}$ ) were drilled into the middle of the KCC with the vertical depths of $28 \mathrm{~m}, 33 \mathrm{~m}$ and $38 \mathrm{~m}$ respectively (Figures 3 and 4). We injected high pressure water continuously into water injection hole $\left(\mathrm{P}_{01}\right.$ or $\left.\mathrm{P}_{03}\right)$ and observed the water flow from the observation hole $\left(\mathrm{P}_{02}\right)$, the permeability of rock mass between the two holes can be determined [7]. A plugging operation is required after the test to avoid interfering with the results of the "water pressure monitoring test". The results of water flow in the X1 at different water pressure conditions are shown in Tables 1 and 2. 


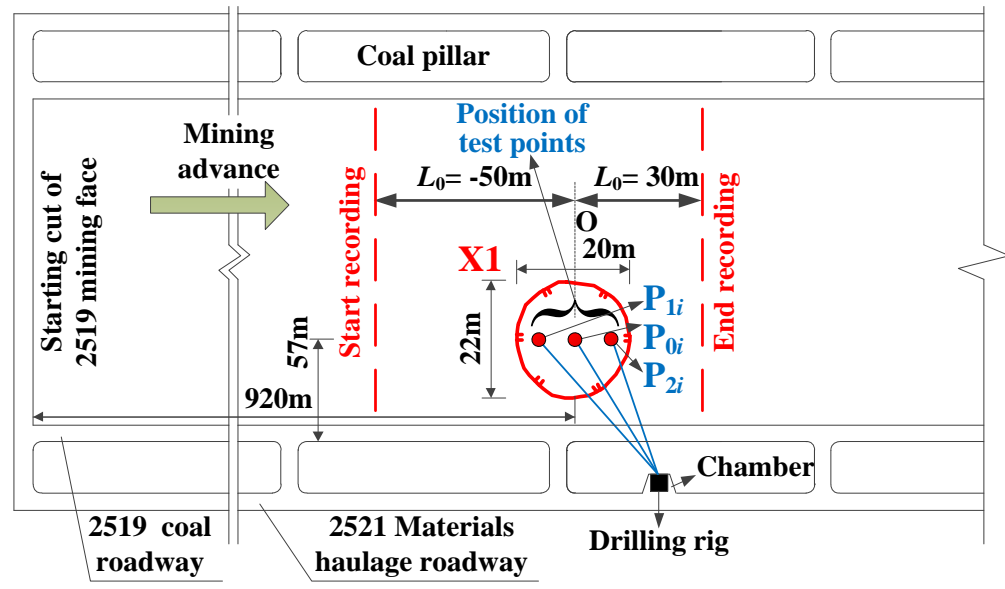

Figure 4. The location of the test points (top view).

Table 1. Connectivity experiment between $P_{01}$ and $P_{02}$.

\begin{tabular}{ccc}
\hline Water Pressure in $\mathbf{P}_{\mathbf{0 1}} \mathbf{M p a}$ & Injection Time/min & Water Flow in $\mathbf{P}_{\mathbf{0 2}} / \mathbf{m}^{\mathbf{3}}$ \\
\hline $0-1$ & 15 & 0.101 \\
$1-2$ & 15 & 0.132 \\
$2-4$ & 15 & 0.227 \\
$4-4.5$ & 15 & 0.413 \\
$4.5-5$ & 15 & 0.682 \\
\hline
\end{tabular}

Table 2. Connectivity experiment between $\mathrm{P}_{03}$ and $\mathrm{P}_{02}$.

\begin{tabular}{ccc}
\hline Water Pressure in $\mathbf{P}_{\mathbf{0 3}} \mathbf{M p a}$ & Injection Time/min & Water Flow in $\mathbf{P}_{\mathbf{0 2}} / \mathbf{m}^{\mathbf{3}}$ \\
\hline $0-2$ & 15 & 0.110 \\
$2-4$ & 15 & 0.152 \\
$4-4.5$ & 15 & 0.235 \\
$4.5-5$ & 15 & 0.416 \\
$5-5.2$ & 15 & 0.635 \\
\hline
\end{tabular}

Tables 1 and 2 indicate that the permeability of the $\mathrm{X} 1$ depends greatly on the water pressure under initial conditions. Although the water pressure in $\mathrm{P}_{01}$ continues to increase, however, the water flow in $\mathrm{P}_{02}$ increased slowly when water injection pressure was less than $5 \mathrm{MPa}$. Once the water pressure exceeded $5 \mathrm{MPa}$, water inrush will occur in $\mathrm{P}_{02}$. The connectivity experiment between $\mathrm{P}_{03}$ and $\mathrm{P}_{02}$ has similar change laws, while the water inrush phenomenon occurred when water pressure in $\mathrm{P}_{03}$ reached $5.5 \mathrm{MPa}$. Compared the two groups of connectivity test, the final water inflow in $\mathrm{P}_{02}$ ( $\mathrm{P}_{01}$ test) was more than that of the $\mathrm{P}_{02}$ ( $\mathrm{P}_{03}$ test), and the water pressure in $\mathrm{P}_{01}$ hole is less than $\mathrm{P}_{03}$.

The above results indicate that the permeability between the $\mathrm{P}_{03}$ and $\mathrm{P}_{02}$ is higher than that between the $\mathrm{P}_{01}$ and $\mathrm{P}_{02}$ in the initial state. However, the ultimate permeability between the $\mathrm{P}_{03}$ and $\mathrm{P}_{02}$ is less than that between the $\mathrm{P}_{01}$ and $\mathrm{P}_{02}$ due to the confining pressure in the former section higher than that in the latter section. In other words, the water blocking capacity of X1 increases with the increase of confining pressure.

In addition, as shown in Tables 1 and 2, the rock pillar with $5 \mathrm{~m}$ long in the $\mathrm{X} 1$ cannot withstand a water pressure of more than $5 \mathrm{MPa}$, but the $\mathrm{X} 1$ is still safe under the action of three aquifers after analysis. The main reasons are as follows: (1) the water pressure is only $3 \mathrm{MPa}$ in limestone 1 , and the water pressure in limestone 1 will not exceed $5 \mathrm{MPa}$ under the mining influence (Section 5.1). The water pressure in limestone 3 is $7 \mathrm{MPa}$, but the distance between the coal seam and the limestone 3 is $82 \mathrm{~m}$ (Figure 3). (2) According to the formation process of the KCC and the coring recovery rate (Figure 3), 
we know that the permeability of the $\mathrm{X} 1$ decreases from bottom to top. This internal structure will gradually consume the energy of confined water, and contributes to the water barrier performance of KCC. In a word, the X1 has a certain water blocking capacity, and it is estimated that the water inflow will not exceed the maximum drainage capacity $\left(1100 \mathrm{~m}^{3} / \mathrm{h}\right)$ of the mine when mining face pass through the X1 (Section 5.1). Besides that, there is not much water in fractures in limestone and KCC due to the effect of high confining pressure. However, a certain amount of groundwater is contained in the dissolved pores. And fortunately, the amount and size of pores is small. The method of mining KCC can avoid tunnel re-excavation, pipelines and hydraulic supports re-arrangement, greatly reduce production costs. In summary, we judge that mining $X 1$ is safe, and can improve production efficiency.

\subsection{Water Pressure Monitoring Test in Two Side-Walls}

The channel for groundwater inrush in the KCC is generally located in the side-wall [12]. In the traditional water injection test [4], engineers inject water into several boreholes at the middle of the $\mathrm{KCC}$ in a short time, and test the water flow loss of each borehole. However, for the X1 with certain permeability, the water flow in boreholes will interfere with each other during the water injection test. Considering this drawback, and in order to evaluate the damage thickness at different side-walls, we have developed a new in-situ experiment, that is, water pressure monitoring test in two side-walls.

The basic principle of the test is simple, the more broken the rock, the shorter the time of water pressure relief. We can use this "relief time" to determine the damage thickness of the KCC in two side-walls. The test process is as follows: the drilling rig was placed in the 2521 materials haulage roadway, $950 \mathrm{~m}$ away from the starting cut (Figure 4). We drilled six boreholes at the two side-walls of the $\mathrm{X} 1$, retained the $20 \mathrm{~cm}$ water injection section $\left(\mathrm{P}_{1 i}\right.$ and $\mathrm{P}_{2 i}$ in Figures 3 and 4 , $i=1,2,3$, represented vertical depths of $28 \mathrm{~m}, 33 \mathrm{~m}$ and $38 \mathrm{~m}$, respectively) at the end of each borehole. High pressure water with $3.8 \mathrm{MPa}$ was injected into a hole, and the relief time would be recorded. If the water pressure dissipated, the same steps would be performed in the next hole. The relief time were started to record if the distance between the mining face and the central of $X 1$ is $50 \mathrm{~m}$, and no longer recorded if the distance is over $30 \mathrm{~m}$. This test lasted a month, and the results shown in Figure 5 .

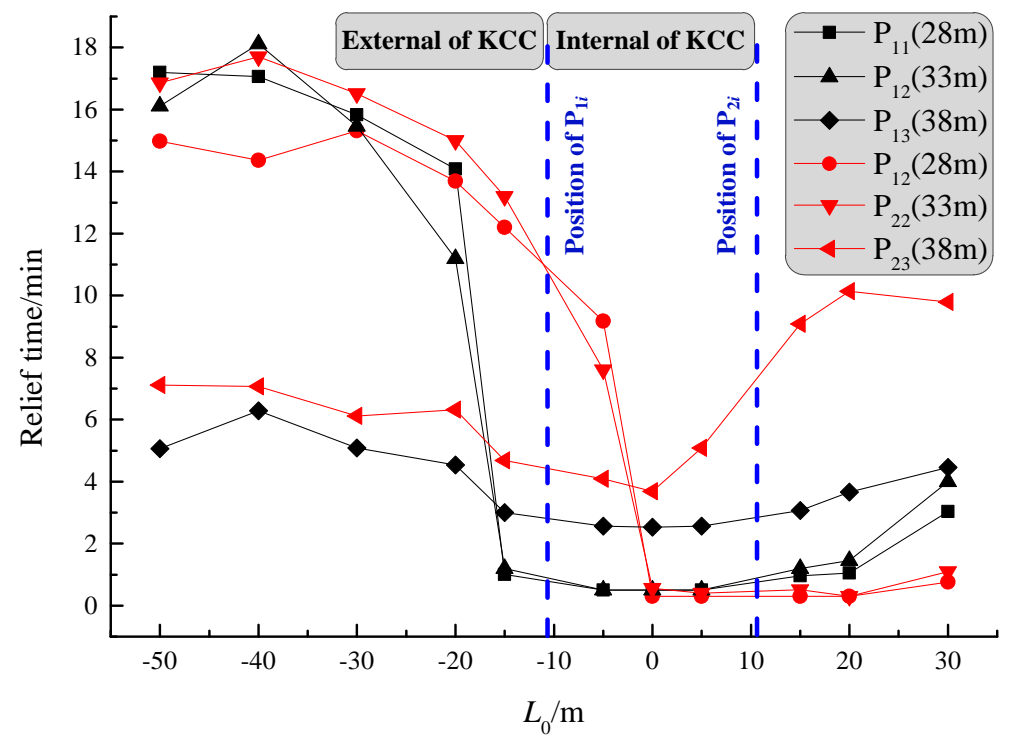

Figure 5. The results of water pressure monitoring test in different vertical depth.

The data indicate that when the distance between the mining face and the $\mathrm{P}_{11}$ (left side of the $\mathrm{X} 1$ ) was more than $15 \mathrm{~m}$, the water pressure would last about 15-18 min. With mining advance, there is a downward trend of the relief time. As the face passes through the $\mathrm{X} 1$, damage appeared at the left side-wall and quickly increased to $28-33 \mathrm{~m}$, and the relief time decreased from 14.08 to $1.01 \mathrm{~min}$ 
$\left(\mathrm{P}_{11}\right)$, which meant that the floor damage degree and range continued to increase; however, for $\mathrm{P}_{13}$, the relief time is over $3.67 \mathrm{~min}$, which means that the maximum damage thickness does not exceed $38 \mathrm{~m}$ or the damage at the depth of $38 \mathrm{~m}$ is slight. The relief time of $\mathrm{P}_{11}$ and $\mathrm{P}_{12}$ achieved a stable value after $0.95 \mathrm{~min}$ and $1.21 \mathrm{~min}$, respectively, until the mining face passes the center of $X 1$ at $15 \mathrm{~m}$. The comparison of test data from boreholes $\mathrm{P}_{2 i}$ and $\mathrm{P}_{1 i}$ showed that the relief time of the two have similar change laws. However, the time in $\mathrm{P}_{13}$ is less than that of $\mathrm{P}_{23}$, indicating that the damage thickness at the left side-wall is greater than that of the right side-wall, and the maximum damage depth is about $38 \mathrm{~m}$.

\section{Constitutive Model and Verification}

Through the above in-situ test, it is possible to accurately obtain the damage thickness at some points during the mining process. However, numerical simulation is needed to obtain the damage thickness as well as stress, damage, seepage, pore water pressure at each point of the $\mathrm{X} 1$. The water inrush mechanism is easily inferred based on the above data.

\subsection{Plastic Damage-Seepage Coupled Model}

The accuracy of the numerical simulation results is closely related to the accuracy of the constitutive model. The complex hydrogeological conditions (Section 2.2) indicate the rationality of PD-S model to explain the mechanism of water inrush from KCC. The traditional constitutive models for studying KCC, such as plastic-seepage theory [4,17], and elastic damage-seepage theory [19], are not applicable to $\mathrm{X} 1$. The main reasons are as follows: (1) for the deep rock mass, the mining influence will produce plastic deformation, so the theory of elastic damage [19] is not appropriate; (2) although the plastic-seepage theory was used in some literature $[4,17]$, they ignored the effect of confining pressure on rock plastic deformation, and the effect of plastic deformation on seepage. In addition, they considered that the permeability coefficient is a function of porosity, which means that it can only be used for the elastic stage of rock.

The three basic equations used in this model are identical to the literature [22], including the equilibrium equation (Equation (1)), the geometric equation (Equation (2)), and the continuous equation (Equation (3)):

$$
\begin{gathered}
\nabla \cdot \sigma^{\mathrm{t}}-F=0 \\
\varepsilon=(\nabla u+u \nabla) / 2 \\
\nabla \cdot q=-\frac{\partial \varepsilon_{\mathrm{v}}}{\partial t}+\frac{n}{K_{\mathrm{f}}} \frac{\partial p_{\mathrm{w}}}{\partial t}
\end{gathered}
$$

where there are eight model parameters: $F$ is the body force vector; $u$ is the displacement vector; $q$ is the seepage velocity vector; $t$ is the time; $\varepsilon_{\mathrm{v}}$ is the volumetric strain; $\varepsilon$ is the strain tensor; $\sigma^{\mathrm{t}}$ is the total stress tensor; and $p_{\mathrm{w}}$ is the pore water pressure. There are two fitting parameters: $n$ is porosity, it can be obtained by the water absorption under the vacuum experimental conditions; $K_{\mathrm{f}}$ is the bulk modulus of water.

However, the remaining equations in the PD-S model, including constitutive equation, strength criteria, plastic potential functions and permeability coefficient equation, are more consistent with the response of deep rock under high confining pressure.

According to the principle of damage mechanics [7], the Boit effective stress theory [8] can be expressed by $\sigma^{\mathrm{t}}, p_{\mathrm{w}}, \varepsilon$ and the effective stress $\sigma^{\mathrm{e}}$, and the relation is shown in Equation (4):

$$
\sigma^{\mathrm{t}}=\sigma^{\mathrm{e}}+\alpha p_{\mathrm{w}}=(1-d) D_{0}\left(\varepsilon-\varepsilon_{\mathrm{p}}\right)+\alpha p_{\mathrm{w}}
$$

where there are two fitting parameters: $\alpha$ is the effective-stress coefficient, determines the effect of pore pressure on rock and can be defined as $\alpha=1-K^{\prime} / K_{\mathrm{s}}, K_{s}$ is the effective bulk modulus of the solid constituent, and $K^{\prime}$ is the drained bulk modulus of the porous medium [14]; $D_{0}$ is the undamaged 
elastic stiffness matrix, we can get it by elasticity theory [23]. The remaining parameters belong to the model parameters: $\varepsilon_{\mathrm{p}}$ is the plastic strain vector; $d$ is the damage value, which is the function of model parameter $\hat{\gamma}_{\mathrm{p}}^{\mathrm{eq}}$, and:

$$
d=\left(e^{-\hat{\gamma}_{\mathrm{p}}^{\mathrm{eq}} / a}-1\right) /\left(e^{-1 / a}-1\right)
$$

where $\hat{\gamma}_{\mathrm{p}}^{\mathrm{eq}}$ is a function of confining pressure $p_{\mathrm{c}}$, and $\hat{\gamma}_{\mathrm{p}}^{\mathrm{eq}}=\int \mathrm{d} \gamma_{\mathrm{p}}^{\mathrm{eq}} /\left[A_{1}\left(\frac{p_{\mathrm{c}}}{\sigma_{\mathrm{c}}}\right)+A_{2}\right]$, its range is $0-1$. $\gamma_{\mathrm{p}}^{\mathrm{eq}}$ is the equivalent shear plastic strain; $\sigma_{\mathrm{c}}$ is uniaxial compressive strength; $a, A_{1}$ and $A_{2}$ are constant, and can be obtained as follows: through the cyclic loading and unloading experiment, we can get the plastic deformation and the elastic modulus during each cycle, so that the curves of $d-\gamma_{\mathrm{p}}^{\text {eq }}$ and $\gamma_{\mathrm{p}}^{\mathrm{eq}}-p_{\mathrm{c}} / \sigma_{\mathrm{c}}$ can be obtained, and then fitting the two curves by linear functions, three material parameters can be obtained.

Based on the modified Mohr-Coulomb yield criterion (Equation (6)), using the non-associated flow rule expressed by Equation (7) [4], the internal variable of $\varepsilon_{\mathrm{p}}$ in the program (Figure 6) can be obtained:

$$
F=\left(\sigma_{\mathrm{n}}^{\mathrm{e}} \tan \varphi^{\prime}+c^{\prime}\right)+d\left(p_{\mathrm{w}} \tan \varphi^{\prime}-c^{\prime}\right)-\tau_{\mathrm{n}}^{\mathrm{e}}=0
$$

where, $\sigma_{\mathrm{n}}^{\mathrm{e}}$ and $\tau_{\mathrm{n}}^{\mathrm{e}}$ are the normal and tangential effective stresses on the shear plane; and the strength parameters $\varphi^{\prime}$ and $c^{\prime}$ (fitting parameters) are the internal friction angle and cohesive force, respectively, both of them are functions of $\hat{\gamma}_{\mathrm{p}}^{\mathrm{eq}}$, and the relation between $\hat{\gamma}_{\mathrm{p}}^{\mathrm{eq}}$ and $\varphi^{\prime}$ and $c^{\prime}$ can be obtained by the following method: (a) by cyclic loading and unloading test, the deviatoric stress and plastic strain under different confining pressure can be obtained. (b) Take equal interval value of $\hat{\gamma}_{\mathrm{p}}^{\mathrm{eq}}$, the deviatoric stress is linearly interpolated according to the corresponding $\hat{\gamma}_{p}^{\mathrm{eq}}$, thus the deviatoric stress in the same $\hat{\gamma}_{p}^{e q}$ under different confining pressures can be obtained. (c) according to the above data, the values of $\varphi^{\prime}$ and $c^{\prime}$ in Mohr-Coulomb criterion $\left(\sigma_{1}=\frac{2 c^{\prime} \cos \varphi^{\prime}}{1-\sin \varphi^{\prime}}+\frac{1+\sin \varphi^{\prime}}{1-\sin \varphi^{\prime}} \sigma_{3}\right)$ can be obtained.

The plastic potential function expressed by the effective hydrostatic stress $p^{\mathrm{e}}$ and the effective deviatoric stress $q^{\text {e }}$ (model parameters) can better reflect the geometric characteristics of plastic potential surface (Figure 6), the expression is shown in Equation (7):

$$
G=\sqrt{\left(\delta c^{\prime}{ }_{0} \tan \psi\right)^{2}+\left(R q^{\mathrm{e}}\right)^{2}}-p^{\mathrm{e}} \tan \psi
$$

where the parameters are fitting parameters except for $p^{\mathrm{e}}$ and $q^{\mathrm{e}} . \delta$ is eccentricity, which defines the rate at which the function approaches the asymptote, $\delta=0.1$ [24]; $c_{0}^{\prime}$ is the cohesion without plastic deformation; $\psi$ is the dilation angle measured in the $p^{\mathrm{e}}-q^{\mathrm{e}}$ plane at high confining pressure; $c^{\prime}{ }_{0}$ and $\psi$ can be obtained by cyclic loading and unloading test. $R$ controls the shape of the plastic potential surface in the deflection plane [24], and:

$$
R=\frac{R_{c}\left[4\left(1-e^{2}\right) \cos ^{2} \theta+(2 e-1)^{2}\right]}{2\left(1-e^{2}\right) \cos \theta+(2 e-1) \sqrt{4\left(1-e^{2}\right) \cos ^{2} \theta+5 e^{2}-4 e}}
$$

where $R_{\mathrm{c}}$ is the polar diameter under the polar coordinate system, its value can be obtained by the conventional triaxial test; the $\theta$ is the polar angle; $e$ is the eccentricity of the partial plane, which controls the shape of the plastic potential surface in the range of $\theta=0-\pi / 3$. Compared with a variety of strength criteria, such as Matsuoka-Nakai [25], Lade [26], Yao [27] and Yu [28], the criteria used in the DP-S model are relatively conservative (Figure 6). For the accident of water inrush from KCC, it is safer to choose this strength criterion. 


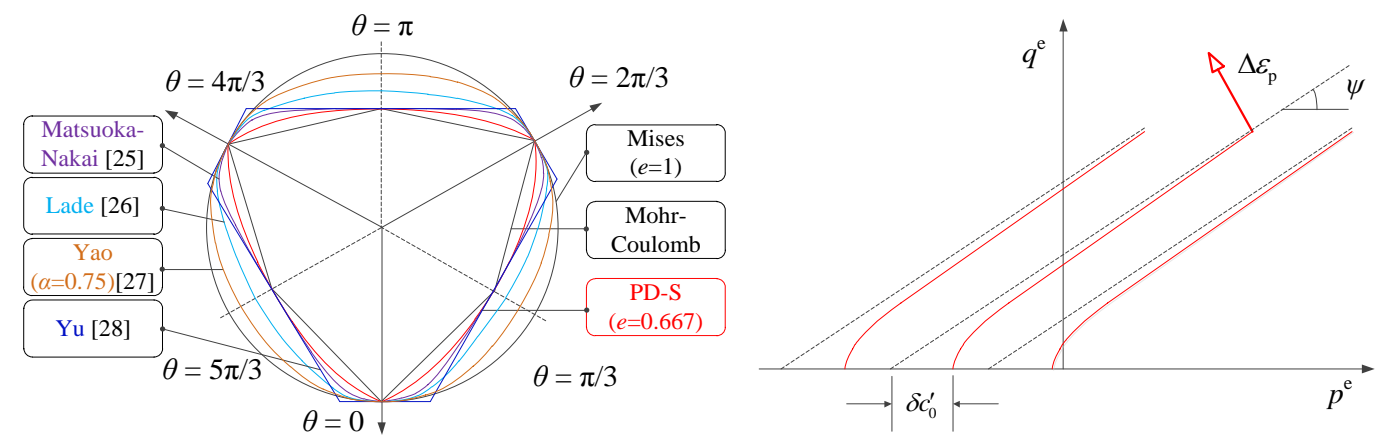

Figure 6. Shape of yield surface in deviatoric plane and meridian plane.

In order to get the expression of the permeability coefficient, we need a simplified hydraulic calculation model. Figure 7a shows the results of scanning electron microscopy (SEM) of rock samples when they are loaded to failure $\left(p_{\mathrm{c}}=10 \mathrm{MPa}\right)$. Figure $7 \mathrm{~b}$ shows that the rock sample formed a macroscopic fracture surface after loading. Both the results of mesoscopic test and the macroscopic observations reflect the fact that the rock sample yielded due to an increase of axial pressure, creating a rupture surface (damaged part) and two rock blocks (non-damaged part). The angle between the rupture surface and the horizontal plane is different due to different confining pressure, and the length of the flow path is changed, however, the $k$ of rock sample is mainly determined by the plastic deformation and damage factors $(d)$ [29]. In other words, the model of representative volume element (RVE) shown in Figure 7c can basically reflect the change of the permeability when the plastic deformation and damage grow in the rock sample. For the non-damaged part, the permeability is marked as $k_{1}$, and the permeability of damaged part is marked as $k_{2}$. For undamaged rock without plastic deformation $\left(\varepsilon_{\mathrm{p}}=0\right)$, the permeability coefficient $k$ is mainly determined by porosity $n$ and elastic volume strain $\varepsilon_{\mathrm{ve}}$ [22]. According to the cube law of fracture seepage and the definition of permeability coefficient [30], we can deduce the permeability coefficient $k$ of the RVE. The equation is as follows:

$$
k=\left\{\begin{array}{c}
k_{1}\left\{\left(1+\varepsilon_{\mathrm{ve}}\right)^{3} / n-(1-n) /\left[n\left(1+\varepsilon_{\mathrm{ve}}\right)^{1 / 3}\right]\right\}, \varepsilon_{\mathrm{p}}=0 \\
(1-d) k_{1}+d k_{2}\left(1+d \hat{\varepsilon}_{\mathrm{vp}}\right)^{3}, \varepsilon_{\mathrm{p}}>0
\end{array}\right.
$$

where, $n$ is the porosity; $\varepsilon_{\mathrm{ve}}$ is the elastic volume strain; $0 \leq \hat{\varepsilon}_{\mathrm{vp}} \leq 1$, is a function of confining pressure $p_{\mathrm{c}}$, and $\hat{\varepsilon}_{\mathrm{vp}}=\int \mathrm{d} \varepsilon_{\mathrm{vp}} /\left[B_{1}\left(p_{\mathrm{c}} / \sigma_{\mathrm{c}}\right)+B_{2}\right], \varepsilon_{\mathrm{vp}}$ is the absolute value of plastic volume strain, $\sigma_{\mathrm{c}}$ is uniaxial compressive strength, the method of obtaining $B_{1}$ and $B_{2}$ is the same as that of $A_{1}$ and $A_{2}$.

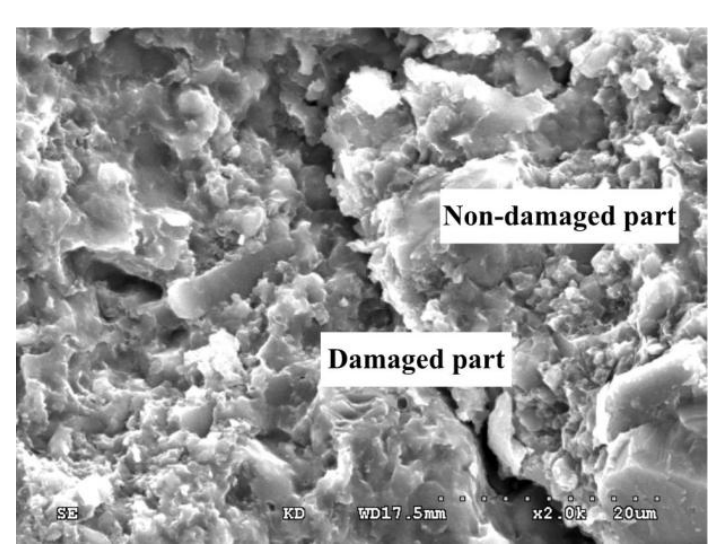

(a)

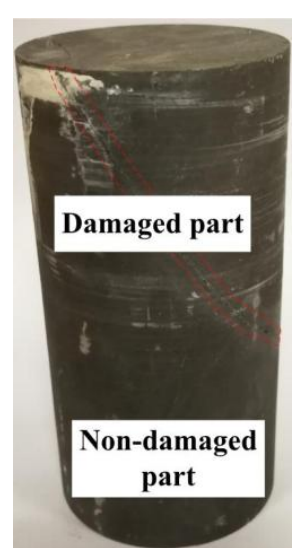

(b)

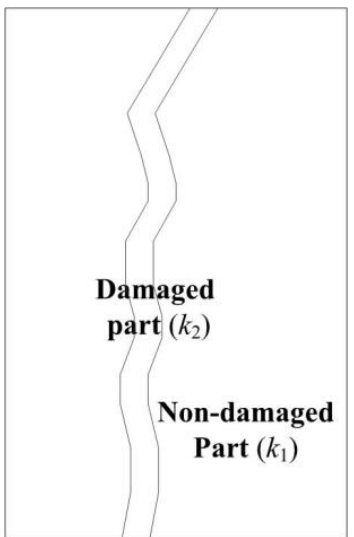

(c)

Figure 7. Simplified calculation model of $k$. (a) microscopic fracture surface; (b) macroscopic fracture surface; (c) RVE model. 
Based on above equations, the PD-S model is established, and the numerical simulation process is shown in Figure 8.

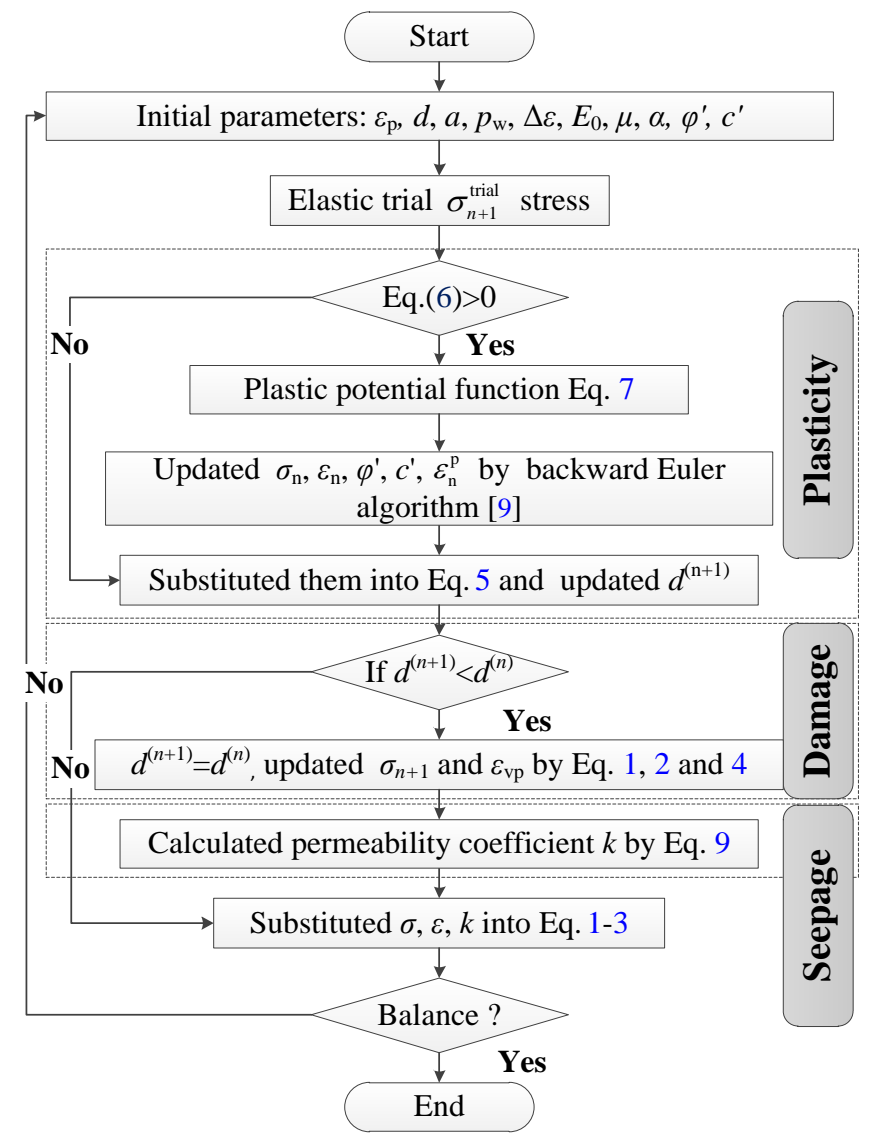

Figure 8. Numerical calculation process of PD-S model.

\subsection{Validation by Laboratory Tests}

Laboratory tests are an effective means of validating a new constitutive model. Taking sandstone as an example, the verification process of the PD-S model is illustrated. For numerical simulations, calculation model is established in the finite element software ABAQUS, the parameters of rock specimen (Table 3) can be obtained by cyclic loading and unloading tests and permeability tests. The results obtained by the two methods are shown in Figure 9. The results of calculation are close to that of test, which shows the rationality of the PD-S model.

Table 3. Calculation parameters of sandstone (rock samples).

\begin{tabular}{lccccccccccccccc}
\hline $\mathrm{E}_{0} / \mathrm{GPa}$ & $\mu$ & $e$ & $a$ & $\psi /^{\circ}$ & $c^{\prime} / \mathrm{MPa}$ & $\phi^{\prime} /{ }^{\circ}$ & $p_{\mathrm{w}} / \mathrm{MPa}$ & $k_{0}\left(k_{1}\right) / \mathrm{ms}^{-1}$ & $k_{2} / \mathrm{ms}^{-1}$ & $\alpha$ & $n / \%$ & $A_{1}$ & $A_{2}$ & $B_{1}$ & $B_{2}$ \\
\hline 20.40 & 0.26 & 0.667 & 0.0106 & 23 & 25.2 & 32 & 3.5 & $1.98 \times 10^{-12}$ & $4.56 \times 10^{-9}$ & 0.76 & 3.1 & 7.62 & 0.3 & 6.17 & 0.54 \\
\hline
\end{tabular}




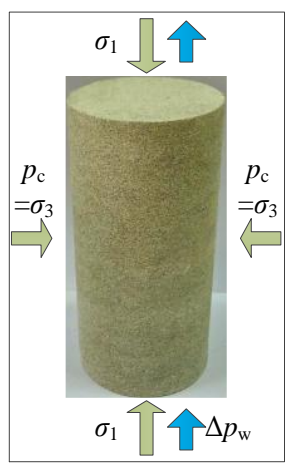

(a) Laboratory test

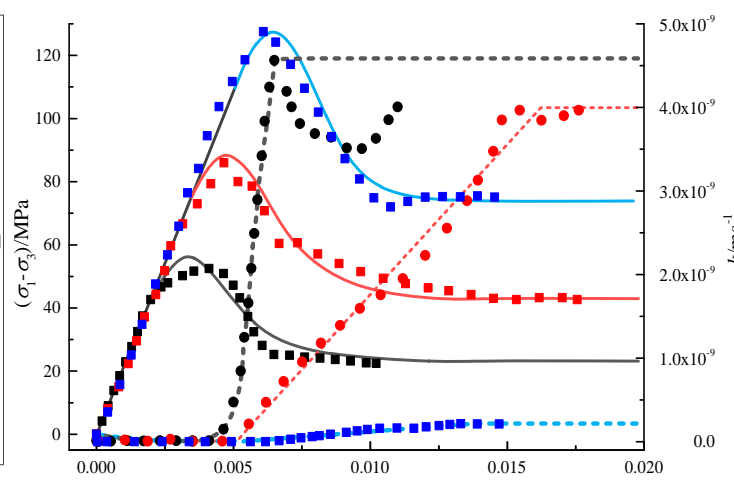

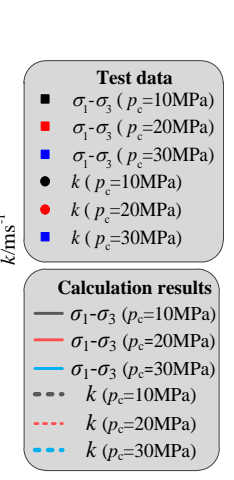

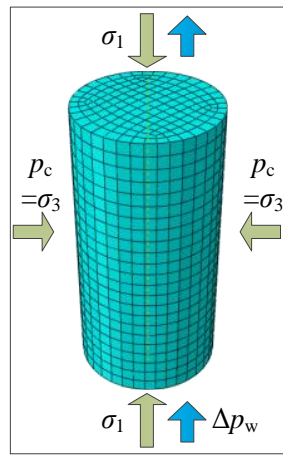

(b) Numerical simulation

Figure 9. Comparison of experimental and calculated results under different confining pressures.

As shown in Figure 9, the stress-strain curves calculated by PD-S model agree well with the experimental results, indicating that the strength criterion, the non-associated flow rule and the mechanical parameters adopted in the model are appropriate. Similarly, the calculated values of $k-\varepsilon_{1}$ are close to the experimental results under high confining pressure $\left(p_{\mathrm{c}} \geq 20 \mathrm{MPa}\right)$, which indicates that the PD-S model and the calculation parameters are reasonable. However, in the condition of low confining pressure $\left(p_{\mathrm{c}} \leq 10 \mathrm{MPa}\right)$, there is a discrepancy between the predicted value and the measured value at the end of the curve, and the reason is as follows: In the process of triaxial compression test, the rock sample breaks down at the softening section after the peak stress, and cause the permeability coefficient $(k)$ to increase sharply. The confining pressure $\left(p_{\mathrm{c}}\right)$ has a significant impact on the $k$ in high confining pressure. Although the rock failed, it is difficult for the dislocation of rock blocks on both sides of the rupture surface to occur under the action of high confining pressure, such as the curves of $k\left(p_{\mathrm{c}}=20 \mathrm{MPa}\right)$ and $k\left(p_{\mathrm{c}}=30 \mathrm{MPa}\right)$. However, under low confining pressure, $p_{\mathrm{c}}$ has little effect on the crack width after rock fracture, and the $k$ increases first, then decreases and then increases: (1) when the axial displacement is applied, the fracture surface is uneven, the crack width increases gradually, and the $k$ increases rapidly (Figure 10b). (2) As the axial displacement continues to increase, the rock blocks on both sides of fracture surface have a relative displacement, if the two "fit each other", that is, the peak of a rock block is close to the trough of another rock block, making the fissure width decrease, thus the $k$ decreases (Figure 10c). (3) If the axial displacement continues to increase, the peaks of two rock blocks are closed, the crack width increases, the $k$ increases (Figure 10d).
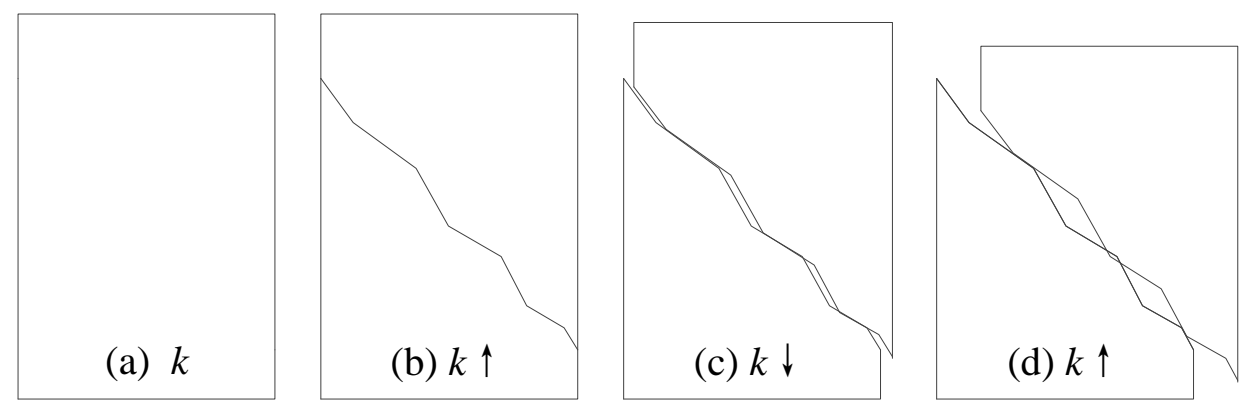

Figure 10. Fracture morphology and variation of permeability coefficient of rock under low confining pressure. (a) Intact rock sample; (b) Cracks appear in the rock sample and the $k$ value increase; (c) The rock blocks on both sides of the rupture face slide and agree with each other, and the $k$ value decreases; (d) The crack width increases under low confining pressure, and the $k$ value increases. 


\section{Results and Discussion}

\subsection{Material Parameters and Calculation Results}

The material parameters of the other materials can be obtained by cyclic loading and unloading tests and seepage tests under different confining pressures as described in Section 4.2. However, these parameters need to be reduced to one-sixth to one-tenth due to the presence of cracks in the natural rock mass [31]. In the process of mining advance, the goaf area is filled by a soft elastic material to simulate the support capability of the fallen rock from the roof. Young's modulus for this material is set at $470 \mathrm{MPa}$, and Poisson's ratio is 0.25 [32]. The physical properties (or coring recovery rate) at different sections of the $\mathrm{X} 1$ are different (Figure 3), leading to the differences of the mechanical and hydraulic properties. Thus we defined the calculation parameters of the different parts of the X1. As shown in Table 4.

As mentioned above, the confining pressure $p_{\mathrm{c}}$ affects the plastic strain $\hat{\gamma}_{\mathrm{p}}^{\text {eq }}$ and $\hat{\varepsilon}_{\mathrm{p}}$ (Equation (7)), thereby affecting the permeability coefficient $k$ (Equation (9)), the damage variable $d$ (Equation (5)), as well as the strength parameters $\varphi^{\prime}$ and $c^{\prime}$ (Equation (6)). The effect of $p_{\mathrm{c}}$ on the $\hat{\gamma}_{\mathrm{p}}^{\text {eq }}$ and $\hat{\varepsilon}_{\mathrm{p}}$ can be determined by $A_{1}, A_{2}, B_{1}, B_{2}$ in Table 4 , while the relationship between the $\hat{\gamma}_{\mathrm{p}}^{\mathrm{eq}}, \hat{\varepsilon}_{\mathrm{p}}$ and $k, \varphi^{\prime}$ and $c^{\prime}$ are shown in Figure 11. And the relation between $\varphi^{\prime}, c^{\prime}$ and $\hat{\gamma}_{\mathrm{p}}^{\mathrm{eq}}$ can be obtained by the statements in Section 4.1. It should be noted that, the rock below the limestone 1 and the lower part of $X 1$ does not undergo plastic deformation by trial, so just showing the relation of $\hat{\varepsilon}_{\mathrm{p}}-k, \hat{\gamma}_{\mathrm{p}}^{\mathrm{eq}}-c$ and $\hat{\gamma}_{\mathrm{p}}^{\mathrm{eq}}-\varphi^{\prime}$ of sandstone, the upper and middle part of X1.

According to the geological and hydrogeology conditions of the 2519 mining face (Figure 3), a plane strain numerical model with length of $300 \mathrm{~m}$ and height of $200 \mathrm{~m}$ was established. This model assumed that the longitudinal profile of the $\mathrm{X} 1$ was trapezoidal, with a top side $12.6 \mathrm{~m}$, a bottom side $36 \mathrm{~m}$ and a height of $140 \mathrm{~m}$, as shown in Figure 12. To obtain the mechanical and hydraulic responses, reasonable boundary conditions are established for the numerical model. Pressures of 17.7 MPa and 28.6 MPa were applied on the top and left and right boundary to simulate the vertical stress (or confining pressure) from the overburden and tectonic stress in the syncline basin (Figure 2), respectively, while pore water pressures of $6.5 \mathrm{MPa}, 3.3 \mathrm{MPa}$ and $3.0 \mathrm{MPa}$ were applied in the three limestone aquifers from bottom to top. The vertical displacement constraints were applied to the bottom boundary of the model. Based on measured data, $20 \mathrm{~m}$ length was added after the first roof caving of $32 \mathrm{~m}$, and backfill of $12 \mathrm{~m}$ length was repeated added in periodic caving. In order to explain the mechanism of water inrush from KCC, we chose the distance of mining face at $L_{0}=-15 \mathrm{~m},-7 \mathrm{~m}$, $0 \mathrm{~m}$ before the center of the $\mathrm{X} 1$ and $L_{0}=7 \mathrm{~m}, 15 \mathrm{~m}$ after the $\mathrm{X} 1$, respectively. The results of the shear stress, confining pressure (or vertical stress), damage zone, pore water pressure and seepage vector were analyzed, as shown in Figure 12. 
Table 4. Material parameters (rock mass).

\begin{tabular}{|c|c|c|c|c|c|c|c|c|c|c|c|c|c|c|c|c|}
\hline & $E_{0} / \mathrm{GPa}$ & $\mu$ & $e$ & $a$ & $\psi 1^{\circ}$ & $c^{\prime} / \mathrm{MPa}$ & $\varphi^{\prime} /^{\circ}$ & $p_{\mathrm{w}} / \mathrm{MPa}$ & $k_{0}\left(k_{1}\right) / \mathrm{ms}^{-1}$ & $k_{2} / \mathrm{ms}^{-1}$ & $\alpha$ & $n / \%$ & $A_{1}$ & $A_{2}$ & $B_{1}$ & $B_{2}$ \\
\hline Coal & 1.52 & 0.25 & 0.667 & 0.11 & 20 & 10.2 & 23 & 0 & $9.73 \times 10^{-12}$ & $7.17 \times 10^{-9}$ & 0.01 & 3.0 & 4.12 & 0.21 & 4.83 & 0.37 \\
\hline Mudstone & 1.31 & 0.32 & 0.667 & 0.15 & 17 & 4.7 & 21 & 0 & $3.62 \times 10^{-12}$ & $6.18 \times 10^{-9}$ & 0.01 & 2.5 & 3.16 & 0.12 & 2.23 & 0.20 \\
\hline Sandstone & 8.73 & 0.26 & 0.667 & 0.010 & 22 & 15.2 & 28 & 0 & $9.37 \times 10^{-10}$ & $1.04 \times 10^{-7}$ & 0.80 & 8 & 7.82 & 0.33 & 6.06 & 0.74 \\
\hline Limestone & 16.7 & 0.22 & 0.667 & 0.007 & 28 & 18.7 & 35 & $3.0 / 3.3 / 7.0$ & $1.05 \times 10^{-9}$ & $9.25 \times 10^{-6}$ & 0.85 & 8.3 & 9.31 & 0.45 & 7.57 & 0.82 \\
\hline Upper X1 & 1.03 & 0.25 & 0.667 & 0.12 & 20 & 5.3 & 26 & 2.0 & $4.76 \times 10^{-9}$ & $3.24 \times 10^{-6}$ & 0.88 & 7.2 & 2.86 & 0.14 & 2.16 & 0.30 \\
\hline Middle X1 & 0.95 & 0.30 & 0.667 & 0.15 & 18 & 3.0 & 23 & 3.3 & $8.5 \times 10^{-9}$ & $7.18 \times 10^{-6}$ & 0.91 & 8.5 & 3.58 & 0.20 & 2.54 & 0.25 \\
\hline Lower X1 & 0.78 & 0.32 & 0.667 & 0.22 & 12 & 2.1 & 18 & 7.0 & $4.36 \times 10^{-8}$ & $8.23 \times 10^{-5}$ & 0.97 & 9.6 & 4.64 & 0.37 & 3.66 & 0.28 \\
\hline
\end{tabular}




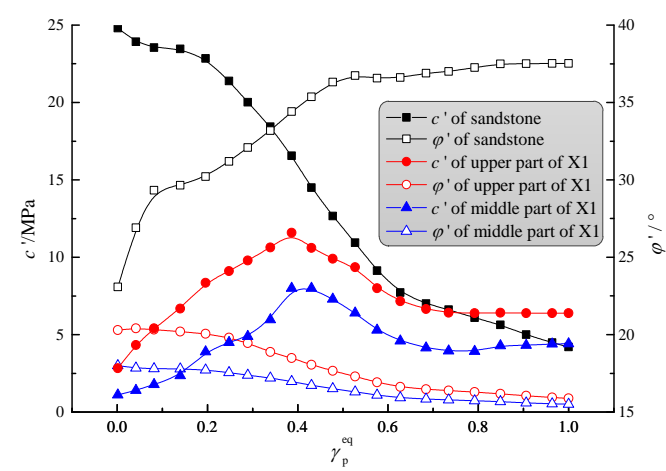

(a)

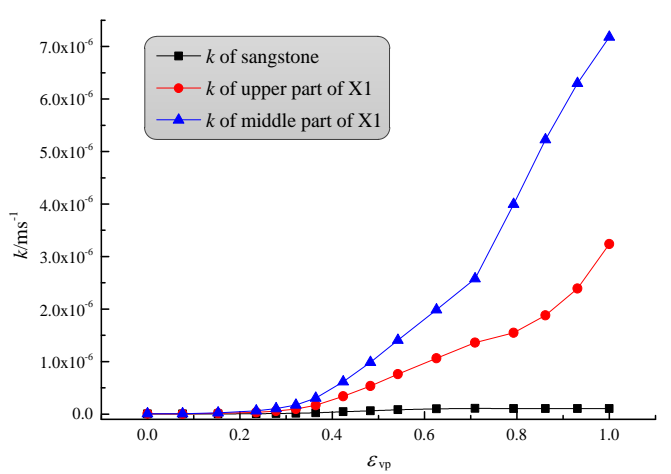

(b)

Figure 11. The evolution curve of $c^{\prime}, \varphi^{\prime}$ and $k$. (a) The relationship between $c^{\prime}, \varphi^{\prime}$ and $\hat{\gamma}_{\mathrm{p}}^{\text {eq }}$; (b) The relationship between $k$ and $\hat{\varepsilon}_{\mathrm{vp}}$.

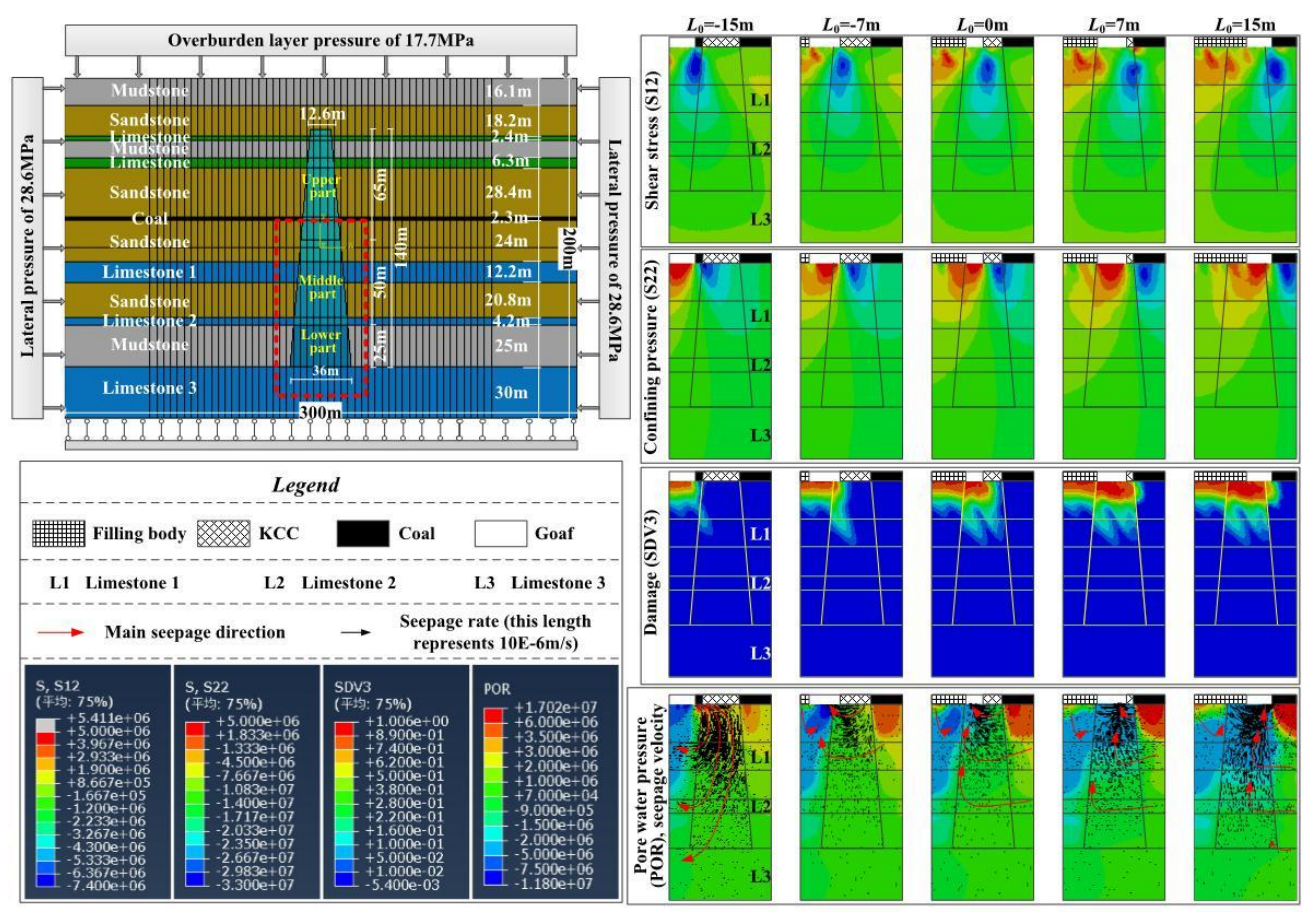

Figure 12. Numerical calculation model and results.

\subsubsection{Shear Stress and Vertical Stress (i.e., Confining Pressure)}

After the coal is excavated, the shear stress concentrates and forms a concentration zone with bubble shape (the first row, blue region, Figure 12) at the front of the coal face. Meanwhile the KCC under the goaf experiences a confining pressure release and forms a relief area with a flat elliptical shape (the second row, red region, Figure 12). The distribution of shear stress and confining pressure changes as mining advances. When $L_{0}<-38 \mathrm{~m}$ (Figure 4 ), the stress in the column varies little. However, in the range of $-15 \mathrm{~m}<L_{0}<15 \mathrm{~m}$, the stress in the column changed dramatically. The maximum shear stress increased from 0.014 $\mathrm{MPa}$ (the initial state) to $6.28 \mathrm{MPa}\left(L_{0}=-7.0 \mathrm{~m}\right)$ or $6.69 \mathrm{MPa}\left(L_{0}=7 \mathrm{~m}\right)$, and then the KCC located in the relief area, the confining pressure deduced from $14.2 \mathrm{MPa}$ (the initial state) to 3.59 $\mathrm{MPa}\left(L_{0}=0 \mathrm{~m}\right)$. After experiencing such a special cycle loading and unloading path, damage could appear in the column. 


\subsubsection{Damage Zone}

The damage zone starts from the above shear stress concentration zone, which determines the damage thickness of the $X 1$, while the relief area of confining pressure determines the ultimate damage degree. When the coal face is away from the $\mathrm{X} 1$, the stress within the column changes little, and no damage occurs. When the $L_{0}=-15 \mathrm{~m}$, the damage thickness of the $\mathrm{X} 1$ reaches $31.6 \mathrm{~m}$ suddenly and the corresponding damage zone is focused on the left side-wall. In the range of $-7 \mathrm{~m}<L_{0}<7 \mathrm{~m}$, although the shear stress near the two side-walls is close, the damage thickness at the left wall $(37.7 \mathrm{~m})$ is slightly larger than that of the right wall $(35.1 \mathrm{~m})$ due to the influence of pore water pressure. When $L_{0} \geq 15 \mathrm{~m}$, the maximum damage thickness of the $\mathrm{X} 1$ is maintained at about $37.7 \mathrm{~m}$, this will create a channel for groundwater inrush between L1 and coal seam (the third row, Figure 11).

It is important to note that in the relief zone, the damage degree continues increasing as the confining pressure decreases. Although this change is evident only in the depth range within $14 \mathrm{~m}$ of the floor near the free face of the goaf, the damage increase can cause drastic changes of the permeability coefficient of the KCC according to Equations (5) and (9), leading to the changes in pore water pressure and seepage velocity in the $\mathrm{X} 1$.

\subsubsection{Pore Water Pressure and Seepage Vector}

As mining advances, the pore water pressure in the KCC strongly depends on the confining pressure. Therefore, the distribution law of the two is similar. When $L_{0}<-26 \mathrm{~m}$, the pore water pressure in the $\mathrm{X} 1$ is almost unchanged. The maximum water pressure at the left wall increased from 2.8 $\mathrm{MPa}$ to $4.9 \mathrm{MPa}$ when $L_{0}=-15 \mathrm{~m}$. Once the coal face passes through the left wall $\left(L_{0}=-7 \mathrm{~m}\right)$, the water pressure drops rapidly to $-13.1 \mathrm{MPa}$. However, the phenomenon that the pore pressure increases first and then decreases does not occur at the right wall position due to the good permeability of the X1. The minimum pore pressure is $-14.2 \mathrm{MPa}$ when $L_{0}=15 \mathrm{~m}$, the negative pore water pressure combined with the reduced confining pressure exacerbates the damage degree of the rock at the right wall.

The seepage velocity vector is the result of the combined action of the above factors (Equation (9)). When $-15 \mathrm{~m}<L_{0}<-7 \mathrm{~m}$, the high water pressure at the front of the coal face pushes the water in the $\mathrm{X} 1$ into limestone 1,2, and even 3 . The groundwater flows to the lower part of goaf along the limestone stratum, rapidly enters the low water pressure area and causes the water inrush from sandstone floor. In this process, the $\mathrm{X} 1$ acts as a vertical aquifer. However, the $\mathrm{X} 1$ acts as a dangerous vertical water-conducting channel when $-7 \mathrm{~m}<L_{0}<15 \mathrm{~m}$. At this moment, the high water pressure area is located outside the X1, and drives the water in the limestone aquifer to enter the X1. Meanwhile the water in sandstone also enters the $\mathrm{X} 1$ under the influence of filling body, and emit from the goaf with low water pressure. The seepage rate reached the maximum at the left wall, $8.4 \times 10^{-7} \mathrm{~m} / \mathrm{s}$ $\left(L_{0}=-3 \mathrm{~m}\right)$. While the seepage velocity is $6.2 \times 10^{-7} \mathrm{~m} / \mathrm{s}\left(L_{0}=10 \mathrm{~m}\right)$ at the right wall. Although the seepage velocity is small, but the $\mathrm{X} 1$ has a greater seepage area and a smaller confining pressure at $L_{0}=10 \mathrm{~m}$, resulting in the water inflow up to $53.8 \mathrm{~m}^{3} / \mathrm{h}$, and the water inflow in left side-wall is only $32.5 \mathrm{~m}^{3} / \mathrm{h}$. Therefore, the right side-wall has a greater risk of water inrush.

\subsection{Discussion}

In this article, we take Chensilou mine as an example, and study the mechanism of water inrush from KCC in complicated geological conditions by a series of methods, including connectivity experiments, water pressure monitoring tests in two side-walls, and numerical simulations based on the PD-S model. Connectivity experiments are an important in-situ test to ensure the safety of mining faces under the influence of KCC. The results obtained by the other two methods show that the KCC's damage thickness at the right side-wall is less than that at the left side-wall, where the instantaneous seepage velocity reaches the maximum. However, due to the influence of confining pressure, the most dangerous position is the right side-wall, and the water inflow is larger than that at 
the left wall (Figure 12). This finding is significant because it clearly indicates that the most dangerous position is not in the maximum damage thickness for an inhomogeneous KCC connected three aquifers. The KCC's damage zone, distribution of pore water pressure and seepage vector were obtained by numerical simulation based on the PD-S model, and verified by water pressure monitoring tests in two side-walls. To our knowledge, the constitutive theory considering the effect of confining pressure on rock strength, plastic deformation, damage and seepage, and the method of monitoring the relief time of water pressure were used herein for the first time in searching water inrush mechanism of KCC. As is known, the KCC is subjected to the cyclic loading and unloading during the mining advance [33]. The change of confining pressure could lead to the change of rock strength, plastic strain and permeability coefficient. Elasticity theory $[14,15]$, elastic-plastic theory $[16,17]$ and traditional fluid-solid coupling theory [19] have been used previously for predicting the safety of the mining face. However, the water inrush mechanism in Chensilou mine cannot be concluded from those models because they were conducted by the lack of the influence of confining pressure on permeability coefficient and plastic deformation (Equations (5) and (9)), lack of the influence of pore water pressure on damage and seepage (Equations (4) and (7)), and lack of the influence of complex geological factors, including multiple limestone aquifer and an inhomogeneous KCC (Figure 3 and Table 4). The new method for in-situ test, and the new model verified by laboratory tests (Figure 9), makes the results more meaningful.

To date, most researchers have used "strain methods" for their in situ tests [19,33]. This method could partially explain the change of strain in floor with the mining advance, but the reason for water inrush from KCC is that the development of rock fissures under the influence of mining, and there seems to be no direct relationship between fissures and strain [34]. Although a method of directly testing KCC's damage was reported in a previous study using water injection tests [4], the exact location of the most dangerous position in the KCC was still unclear because they set the test section in the middle of the KCC. In addition, the water inflow in boreholes could interfere with each other during the water injection tests. In order to obtain damage thickness in the two side-walls of the KCC, an improved method named "water pressure monitoring test in two side-walls" has been developed. Through the above in-situ test and numerical simulation method, we obtained that the water inrush from KCC is a cascading and vicious cycle accident (Figure 13).

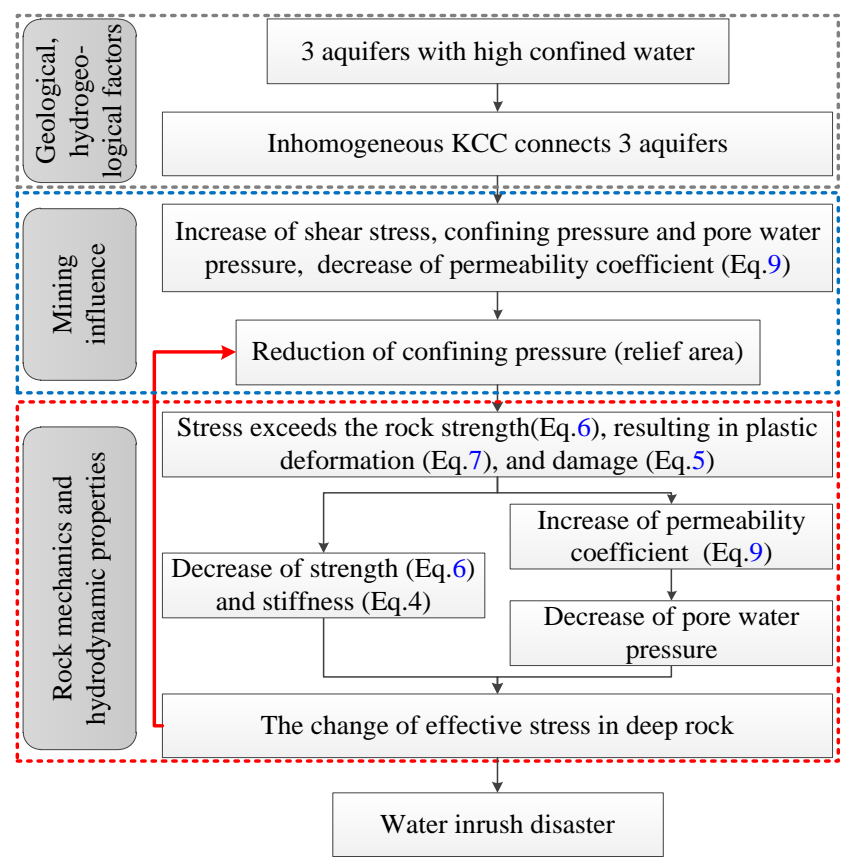

Figure 13. The process of cascade and vicious cycle for water inrush from KCC. 
The PD-S model and water pressure monitoring test could be valuable tools with applications in deep buried, and cyclic loading and unloading conditions, such as coal mining in the seabed [35], and the co-exploitation of uranium, oil, gas, and coal under the influence of watery faults [36].

\section{Conclusions}

The main conclusions drawn from the investigations are summarized as follows:

1. The reasonableness of the in-situ test method determines the accuracy of the test results. Connectivity experiment is an important method to ensure the safety of coal mining. The water pressure monitoring test in two side-walls, which is suitable for good permeability of the KCC, has been developed. According to the relief time of water pressure, the damage thickness of the side-wall far away from the starting cut is smaller than that near the starting cut, and the maximum depth of damage zone reaches limestone 1 .

2. Shear stress is one of the important factors in determining the damage thickness. In the process of mining advance, the shear stress concentration area below the coal face leads to formation of a damage zone, and this phenomenon is more pronounced near the side-wall of KCC due to a strong shear dislocation between the two materials with different mechanical properties. Consistent with the results of in-situ tests, the maximum damage thickness is about $37.7 \mathrm{~m}$, and it is located in the left side-wall.

3. Confining pressure plays a crucial role in the water inrush mechanism of KCC. With the decrease of confining pressure, deviatoric stress can cause further plastic strain increases, rock damage and permeability, and a reduction of strength and stiffness. Meanwhile the pore water pressure changes from positive to negative, and the effective stress in the rock will damage the deeper rock, or force the rock to become more fractured in the damage zone. This broken rock can cause stress changes, especially the confining pressure in the KCC. Thus a cascade of vicious water inrush disaster cycles forms.

Acknowledgments: The author sincerely thanks Wang Qiang at Southeast University for providing workstation and related data access. This work was supported by the Research Innovation Program for College Graduates of Jiangsu Province (KYLX16_0537) and National Natural Science Foundation of China (51323004). The authors would like to thank anonymous referees for their careful reading of this article and valuable suggestions.

Author Contributions: J.W. and Z.M. conceived and designed the experiments; K.M. and G.W. performed the experiments; Y.D. and S.H. analyzed the data; H.B. contributed analysis tools; H.L. wrote the paper.

Conflicts of Interest: The authors declare no conflicts of interest.

\section{References}

1. Booth, C.J. Groundwater as an environmental constraint of longwall coal mining. Environ. Geol. 2006, 49, 796-803. [CrossRef]

2. Odintsev, V.N.; Miletenko, N.A. Water inrush in mines as a consequence of spontaneous hydrofracture. J. Min. Sci. 2015, 51, 423-434. [CrossRef]

3. Istvan, B.; Lucien, D.; Ferenc, S. Bayesian analysis of underground flooding. Water Resour. Res. 1982, 18, 1110-1116.

4. Ma, D.; Miao, X.; Bai, H.; Huang, J.; Pu, H.; Wu, Y.; Zhang, G.; Li, J. Effect of mining on shear sidewall groundwater inrush hazard caused by seepage instability of the penetrated karst collapse pillar. Nat. Hazards 2016, 82, 73-93. [CrossRef]

5. Cook, A.C. Australian Black Coal; Australian Institute of Mining and Metallurgy: Illawarra, Australia, 1975.

6. Huang, Z.; Jiang, Z.; Qian, Z.; Cao, D. Analytical and experimental study of water seepage propagation behavior in the fault. Acta Geodyn. Geomater. 2014, 176, 361-370. [CrossRef]

7. Li, H.; Bai, H.B.; Wu, J.J.; Zhao, H.M.; Ma, K. A method for prevent water inrush from karst collapse column: A case study from sima mine, china. Environ. Earth Sci. 2017, 76, 493. [CrossRef]

8. Bai, H.B.; Ma, D.; Chen, Z.Q. Mechanical behavior of groundwater seepage in karst collapse pillars. Eng. Geol. 2013, 164, 101-106. [CrossRef] 
9. Qian, X.P. The formation of gypsum karst collapse-collum and its hydrogeological significance. Carsologica Sin. 1988, 4, 344-348.

10. Yuan, D. Karstology of China; Geological Publishing House: Beijing, China, 1994.

11. Shi, J.; Lian, D.; Yang, S. A discussion of karst collapse. Geol. Min. Res. North China Mag. 1998, 13, $264-266$.

12. Yin, S.X.; Wu, Q.; Wang, S.X. Water-bearing characteristics and hydro-geological models of karstic collapse columns in north China. Chin. J. Rock. Mech. Eng. 2005, 24, 77-82.

13. Zhang, J.F.; Zhang, H.L.; Meng, D.; Cao, J. Numerical simulation of rock deformation and seepage field with a fully-water karstic collapse column under mining influence. Chin. J. Rock. Mech. Eng. 2009, 28, 77-82.

14. Li, Z.; Feng, G.; Zhai, C. Study on "triangle" water-inrush mode of strong water-guide collapse column. J. Cent. South. Univ. 2016, 23, 2402-2409. [CrossRef]

15. Zhang, C.; Tu, S. Control technology of direct passing karstic collapse pillar in longwall top-coal caving mining. Nat. Hazards 2016, 84, 17-34. [CrossRef]

16. Yin, S.X.; Zhang, J. Impacts of karst paleo-sinkholes on mining and environment in northern China. Environ. Geol. 2005, 48, 1077-1083. [CrossRef]

17. Ou, S.; Wang, L.; Wang, P. Numerical analysis of seepage flow characteristic of collapse column under the influence of mining. Int. J. Min. Sci. Technol. 2013, 23, 237-244. [CrossRef]

18. Zhang, J.C. Investigations of water inrushes from aquifers under coal seams. Int. J. Rock. Mech. Min. Sci. 2005, 42, 350-360. [CrossRef]

19. Zhu, W.C.; Wei, C.H. Numerical simulation on mining-induced water inrushes related to geologic structures using a damage-based hydromechanical model. Environ. Earth Sci. 2011, 62, 43-54. [CrossRef]

20. Liu, E.L.; He, S.M. Effects of cyclic dynamic loading on the mechanical properties of intact rock samples under confining pressure conditions. Eng. Geol. 2012, 125, 81-91. [CrossRef]

21. Bai, H.B.; Miao, X.X. Hydrogeological characteristics and mine water inrush prevention of late Paleozoic coalfields. J. China Univ. Min. Technol. 2016, 45, 1-10.

22. Li, L.C.; Tang, C.A.; Liang, Z.Z.; Ma, T.H.; Zhang, Y.B. Numerical simulation on water inrush process due to activation of collapse columns in coal seam floor. J. Min. Saf. Eng. 2009, 26, 158-162.

23. Boresi, A.P.; Lynn, P.P.; Hung, Y.Y. Elasticity in Engineering Mechanics; Elsevier: Amsterdam, The Netherlands, 2011.

24. Fei, K.; Zhang, J.W. Application of ABAQUS in Geotechnical Engineering; China Water \& Power Press: Beijing, China, 2013.

25. Matsuoka, H.; Nakai, T. Relationship among Tresca, Mises, Mohr-Coulomb and Matsuoka-Nakai failure criteria. Soils Found. 2008, 25, 123-128. [CrossRef]

26. Woodward, P.K. Earth pressure coefficients based on the Lade-Duncan failure criterion. Eng. Struct. 1997, 19, 733-737. [CrossRef]

27. Yao, Y.P.; Zhang, B.Y.; Zhu, J.G. Behaviours, constitutive models and numerical simulation of soils. China Civ. Eng. J. 2012, 45, 127-150.

28. Zan, Y.W.; Yu, M.H. Generalized nonlinear unified strength theory of rock. J. Southwest Jiaotong Univ. 2013, $48,616-624$.

29. Luo, Z.H.; Zhu, Z.D.; Ruan, H.N.; Shi, C. Extraction of microcracks in rock images based on heuristic graph searching and application. Comput. Geosci. 2015, 85, 22-35. [CrossRef]

30. Yin, L.M.; Chen, J.T.; Sun, W.B. Experimental Study on three dimensional coupled stress-seepage law of single fracture. Appl. Mech. Mater. 2013, 353, 524-528. [CrossRef]

31. Peng, S.S. Longwall Mining; Science Press: Beijing, China, 2011.

32. Cheng, Y.M.; Wang, J.A.; Xie, G.X.; Wei, W.B. Three-dimensional analysis of coal barrier pillars in tailgate area adjacent to the fully mechanized top caving mining face. Int. J. Rock. Mech. Min. Sci. 2010, 47, 1372-1383. [CrossRef]

33. Yin, H.; Lefticariu, L.; Wei, J. In situ dynamic monitoring of stress revolution with time and space under coal seam floor during longwall mining. Environ. Earth Sci. 2016, 75, 1249-1260. [CrossRef]

34. Wang, Y.; Yang, W.; Li, M.; Liu, X. Risk assessment of floor water inrush in coal mines based on secondary fuzzy comprehensive evaluation. Int. J. Rock. Mech. Min. Sci. 2012, 52, 50-55. [CrossRef] 
35. Gao, Y.; Zhang, Q.S.; Xu, B.S.; Li, W. Study of mining roof abutment pressure distribution law. Rock Soil Mech. 2010, 31, 1309-1313.

36. Wang, Y.; Yang, W.L.; Deng, J.; Wu, B.L.; Li, Z.Y.; Wang, M.Z. Accumulation system of cohabitating muti-energy minerals and their comprehensive exploration in sedimentary basin-A case study of Ordos basin, NW China. Acta Geol. Sin. 2014, 88, 815-824. 